\title{
The Potential Benefits of Certolizumab Pegol in Patients with Concurrent Psoriatic Arthritis and Chronic Plaque Psoriasis: A Case Series and Review of the Literature
}

\author{
David Rutkowski (1) $\cdot$ Hector Chinoy $\cdot$ Richard B. Warren
}

Received: September 13, 2018 / Published online: March 16, 2019

(C) The Author(s) 2019

\begin{abstract}
Introduction: We review the literature evaluating certolizumab in psoriasis and report our experience of treatment outcomes in a joint dermatology and rheumatology clinic.

Methods: Patients with concomitant psoriatic arthritis (PsA) and psoriasis who had been commenced on certolizumab were included within our retrospective review. Data was collected for patient demographics, Patient Area and Severity Index (PASI), Dermatology Life Quality Index (DLQI) and previous treatments.
\end{abstract}

Enhanced digital features To view enhanced digital features for this article go to https://doi.org/10.6084/ m9.figshare.7777082.

D. Rutkowski $(\varangle) \cdot$ R. B. Warren

The Dermatology Centre, Salford Royal NHS

Foundations Trust, The University of Manchester,

Manchester Academic Health Science Centre,

Manchester, UK

e-mail: david.rutkowski@manchester.ac.uk

H. Chinoy

Rheumatology Department, Salford Royal NHS

Foundation Trust, The University of Manchester,

Manchester Academic Health Science Centre,

Manchester, UK

H. Chinoy · R. B. Warren

National Institute for Health Research Manchester Musculoskeletal Biomedical Research Centre, Central Manchester University Hospitals NHS

Foundation Trust, The University of Manchester, Manchester, UK
The literature was systematically searched using Pubmed and Scopus.

Results: Very recent results from the CIMPASI1 and CIMPASI-2 studies have demonstrated the high efficacy of certolizumab in the treatment of psoriasis at both week 16 and 48. Pooled results from these studies showed a PASI75 at week 16 and week 48 of $82 \%$ and $83.6 \%$ respectively, in the certolizumab $400 \mathrm{mg}$ group. In our cohort of eight patients (two female; six male; median age 49 and mean PASI of 20.8) all had failed at least two systemic non-biologic agents. Objective improvements were observed in seven patients, with five achieving PASI90 and two demonstrating either PASI75 or PASI50.

Conclusion: Certolizumab is efficacious in both psoriasis and PsA, including in patients who are biologic failures, and could be considered as an alternative treatment modality.

Keywords: Certolizumab; Chronic plaque psoriasis; Psoriasis; TNF inhibitors

\section{INTRODUCTION}

Psoriasis is a chronic inflammatory disorder which affects $0.7-2.9 \%$ of the adult European population [1]. Although the exact pathogenesis is still debatable, a complex interaction between genetic and environmental factors triggers an up-regulation of T helper 1 (Th1) and 
17 (Th17) pathways, giving rise to increased levels of tumour necrosis factor (TNF) and IL$17 / 22$ [2, 3]. Biologics specifically targeting these pathways have revolutionized the management of psoriasis and significantly improve patients' quality of life.

At the time of publication, the European Medicines Agency had approved TNF inhibitors (adalimumab, infliximab, etanercept and certolizumab); IL-12/23 inhibitors (ustekinumab); IL-23 inhibitors (guselkumab and tildrakizumab) and the IL-17 inhibitors (brodulumab, secukinumab and ixekizumab). TNF inhibitors collectively remain the most widely used biologics in psoriasis and are considered the current gold standard in the management of PsA, yet their relative efficacies for psoriasis are far more varied [4-6].

Etanercept, a human recombinant TNF receptor p75 protein which binds to both TNF- $\alpha$ and TNF- $\beta$, was one of the first biologics and has been shown to achieve a $75 \%$ or greater improvement from baseline in Patient Area and Severity Index (PASI) score (PASI75) in 34-57\% of patients at week 12 [7-9]. The chimeric monoclonal antibody infliximab binds to soluble and membrane-bound TNF- $\alpha$ and causes a rapid improvement in psoriasis with $75.5 \%$ of patients reaching a PASI75 at week 10 [10-12]. Adalimumab, currently the most commonly prescribed biologic for psoriasis patients, is a fully human, monoclonal antibody that targets both soluble and membrane-bound TNF- $\alpha$, and achieves a PASI75 in 69\% of patients at week 16 $[5,12,13]$.

Despite their short-term clinical effectiveness, the overall drug survival rate for all TNF inhibitors and ustekinumab is only $53 \%$ following 3 years of treatment, based on analysis of 3500 biologic-naïve patients in the British Association of Dermatologists Biologics Intervention Register (BADBIR) [5]. After the first year, drug survival rates for patients on either ustekinumab, adalimumab, etanercept or infliximab were $89 \%, 79 \%, 70 \%$ and $65 \%$ respectively, and further reduced to $75 \%, 59 \%$, $40 \%$ and $35 \%$ after 3 years [5]. This loss of efficacy may in part be due to the development of neutralising antibodies, especially for the monoclonal antibodies infliximab and adalimumab [12, 14-16].

It is the authors' experience, supported by the registry data, that a significant minority of 'difficult to treat' patients exist in whom the conventional biologic repertoire has failed as a result of either primary or secondary failure or adverse events. We report our experience of a joint tertiary dermatology-rheumatology clinic in which patients with significant psoriasis and PsA were treated with certolizumab pegol, a TNF inhibitor currently licensed for the treatment of psoriatic arthritis (PsA) but not for psoriasis in the UK. We will also review the literature in regards to the use of certolizumab for psoriasis.

\section{REVIEW OF A PATIENT DATABASE}

The case notes of patients at a single centre in the North West of England with PsA, who had been commenced on certolizumab prior to December 2016, were identified $(n=58$; Fig. 1$)$. A retrospective review of the case notes revealed eight patients with severe psoriasis where a joint decision between Dermatology and Rheumatology had been made to commence certolizumab as a modality to treat both PsA and chronic plaque psoriasis (CPP) (Table 1). Patients with PsA who were commenced on certolizumab who did not suffer from psoriasis or who had mild to moderate psoriasis not requiring dermatological input were not included $(n=50)$. All patients were commenced on certolizumab $400 \mathrm{mg}$ subcutaneously at week 0 , 2 and 4 followed by $200 \mathrm{mg}$ every 2 weeks thereafter apart from one patient who following induction was commenced on $400 \mathrm{mg}$ every 2 weeks due to the severity of his disease burden (Table 1).

Of the eight patients identified (two female, six male, average age 49 years), seven had severe disease (mean PASI 22.9, DLQI 19.7) and one patient had a PASI of 6 and DLQI of 7. Two patients were biologic-naïve, three (patients 1, 5 and 7) had previously failed one anti-TNF agent (either etanercept or adalimumab) with patient 7 having previously developed anti-drug antibodies (ADAbs) to adalimumab. Three patients (patients 3, 6 and 8) had previously failed 


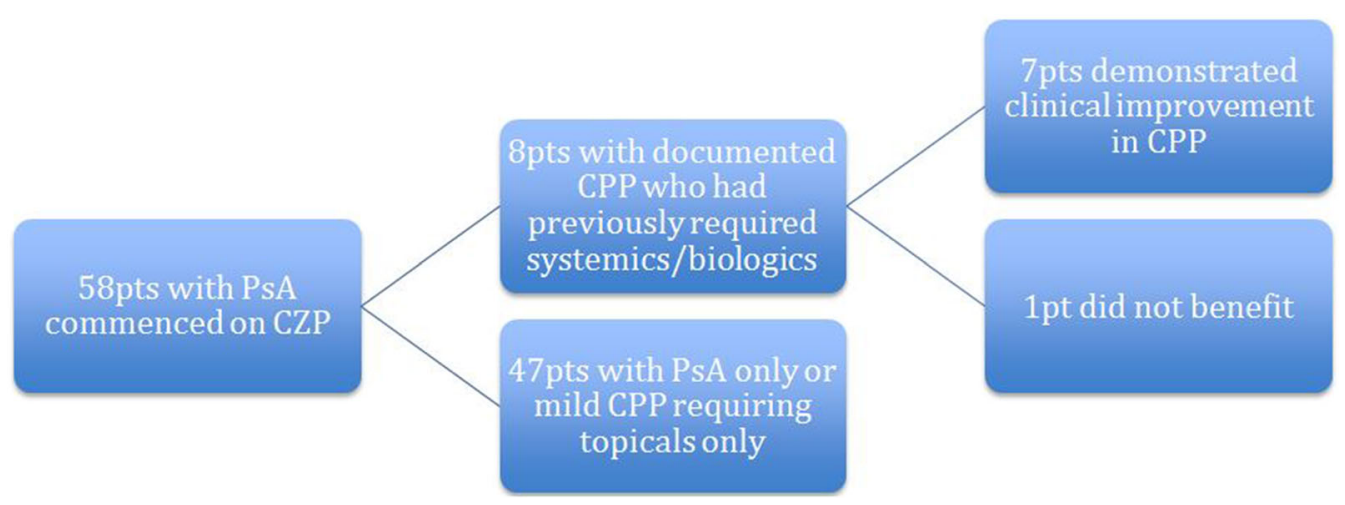

Fig. 1 Schematic representation of the methodology employed. 58 patients who had either been commenced on certolizumab for their PsA up to and including December 2016 at a single centre in the North West of England. A retrospective review of patients notes revealed 8 patients who had concomitant chronic plaque psoriasis which was severe enough to warrant either the use of

multiple biologics including two patients (patient 6 and 8) who had failed four biologics and patient 3 who had previously failed six biologic agents. Of the three patients who had previously failed multiple biologics, all had failed three anti-TNFs (infliximab, adalimumab, etanercept); indeed in one patient we demonstrated low adalimumab drug levels and development of adalimumab drug antibodies prior to switching to certolizumab.

All patients, except for patient 3, demonstrated a positive response to treatment. A PASI90 was achieved in five patients (patients 1, 4, 5, 6 and 7), PASI75 was achieved in patent 8 and PASI50 was achieved in patient 2 despite suffering from moderate disease prior to commencing treatment (baseline PASI 6). Patient 3 suffered from recalcitrant psoriasis and PsA, and had been resistant to multiple systemic agents and biologics. This work was done as an anonymized audit on certolizumab use in a single tertiary referral centre and therefore informed consent was not required.

\section{LITERATURE REVIEW}

A literature search using Pubmed and Scopus for clinical trials of certolizumab in psoriatic patients was performed. Inclusion criteria systemic agents or biologics. Patients with minimal chronic plaque psoriasis who were only on topical treatments were not included. Pt patients, CZP certolizumab, CPP chronic plaque psoriasis, PsA psoriatic arthritis

consisted of trials in which the effect of certolizumab on patients with psoriasis was assessed as either a primary or secondary endpoint. Three studies were identified within the literature and their levels of evidence were assessed according to the Centre of Evidence Based Medicine (see Table 2).

The CIMPASI-1 and CIMPASI-2 are two replicate phase 3 , double-blinded and randomised clinical trials evaluating the efficacy of certolizumab on psoriasis over 144 weeks [15]. In both studies, participants were randomised to either placebo, certolizumab $400 \mathrm{mg}$ every 2 weeks or $200 \mathrm{mg}$ every 2 weeks and subgroups were analysed descriptively on the basis of nonresponder imputation. At week 16, patients in the placebo group who achieved PASI50 but not PASI75 were reassigned to certolizumab $200 \mathrm{mg}$ and patients who failed to achieve PASI50 in the placebo group were reassigned to the certolizumab $400 \mathrm{mg}$ group. Pooled results from both studies demonstrated a PASI75 at week 16 and week 48 of $82 \%$ and $83.6 \%$ respectively in the certzolizumab $400 \mathrm{mg}$ group $(n=175)$; $76.7 \%$ and $70.7 \%$ and in the certolizumab $200 \mathrm{mg}$ group $(n=186)$ and $9.9 \%$ at week 16 in the placebo group $(n=100)$ [15]. Furthermore, PASI90 was achieved at week 16 and week 48 in $52.2 \% / 61.6 \%$ of patient in the $400 \mathrm{mg}$ group; 


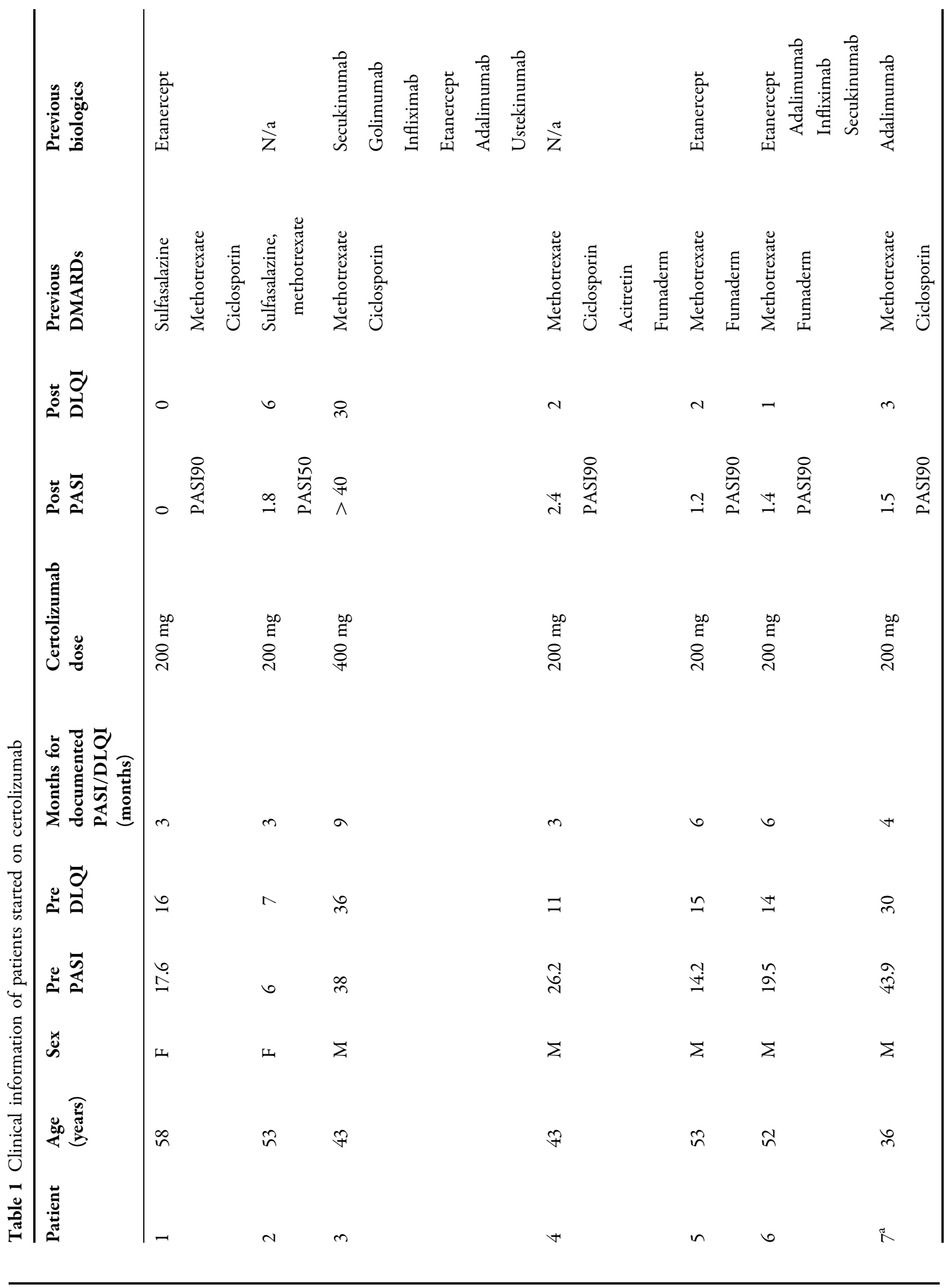




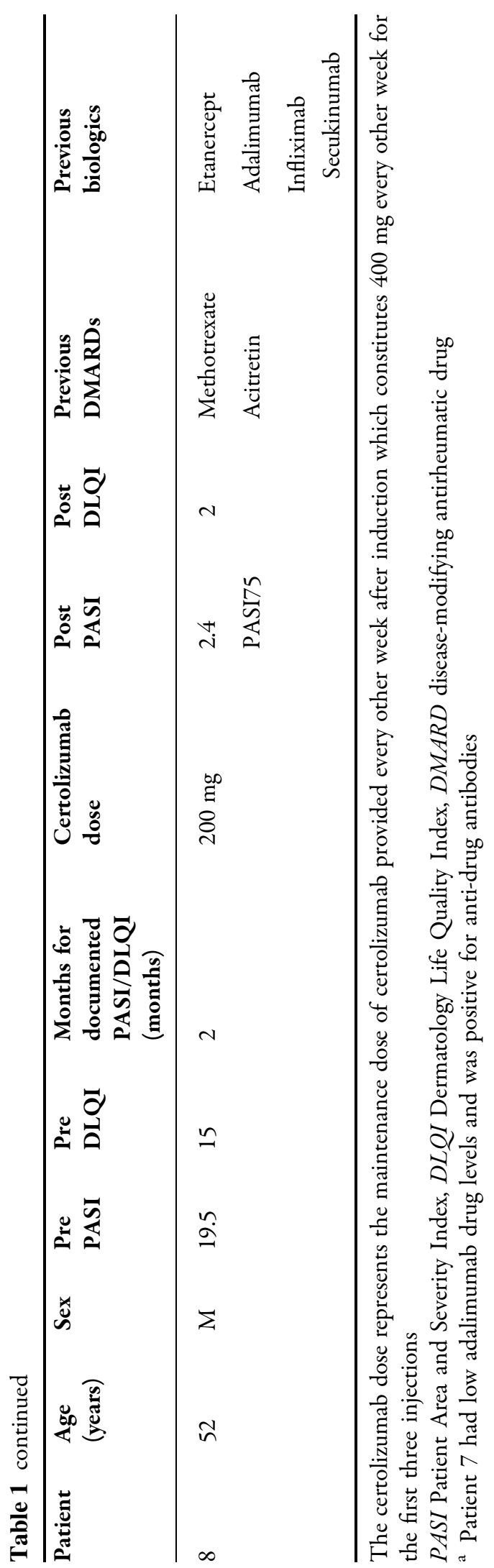

$45.9 \% / 50 \%$ in the certolizumab $200 \mathrm{mg}$ group and $2.5 \%$ in the placebo group at week 16 .

Reich et al. conducted a randomised, placebo-controlled, double-blind phase 2 trial of 176 patients who were induced with certolizumab $400 \mathrm{mg}$ at week 0 followed by either placebo $(n=59)$, certolizumab $400 \mathrm{mg}(n=58)$ or $200 \mathrm{mg}(n=59)$ every other week for a total of 10 weeks. In the placebo controlled group, $7 \%$ of patients achieved PASI75 at week 12 compared to the certolizumab $400 \mathrm{mg}$ and $200 \mathrm{mg}$ groups who achieved PASI75 in 83\% and $75 \%$ and PASI90 in $47 \%$ and $39 \%$ respectively. After week 10, treatment was stopped; those patients who had a loss of PASI greater than $50 \%$ were immediately re-treated at their original dose. Similar efficacy was noted in the re-treatment group with PASI75 noted in $86.5 \%$ and $67.6 \%$ and PASI90 in $48.6 \%$ and $35.3 \%$ in those treated with certolizumab $400 \mathrm{mg}$ and $200 \mathrm{mg}$ respectively [17].

The RAPID-PsA study was a phase 3 randomised multicentre trial in patients with PsA which was double-blinded and placebo-controlled to week 24 and then dose-blinded to week 48 with an open label extension to week 216 [18]. As part of the interim data, results of PASI were published. Patients with psoriasis affecting greater than $3 \%$ of total body surface area (BSA) and PASI greater than 10 were monitored for improvements in PASI75 and PASI90. Dosing regimens included certolizumab $200 \mathrm{mg}$ every 2 weeks $(n=37)$ or $400 \mathrm{mg}(n=34)$ every 4 weeks and the following responses were noted in PASI75, respectively: $81 \%$ and $74 \%$ at week $24,78 \%$ and $77 \%$ at week 48 , and $65 \%$ and $59 \%$ at week 96 [18]. PASI90 was achieved in 59.5\% and $47.1 \%$ at week 24 and in $45.9 \%$ and $47.1 \%$ at week 96 [18]. PASI100 responses were seen in $31.1 \%$ of patients at week 96 . No significant difference was seen between biologic-naïve and patients who had previously had anti-TNF treatment.

\section{DISCUSSION}

Certolizumab pegol is the only pegylated, humanised antigen-binding fragment (Fab) inhibitor of TNF and is recommended for the 
Table 2 Review of certolizumab pegol within the literature

\begin{tabular}{|c|c|c|c|c|}
\hline Author & $\begin{array}{l}\text { Levels } \\
\text { of } \\
\text { evidence }\end{array}$ & Journal (year) & Method & PsO effect \\
\hline $\begin{array}{r}\text { Mease } \\
{[18]}\end{array}$ & 2 & $\begin{array}{l}\text { Rheumatic and } \\
\text { Musculoskeletal } \\
\text { Disease (2015) }\end{array}$ & $\begin{array}{l}\text { Randomised multicentre trial in PsA patients. } \\
\text { Patients received placebo, CZP } 200 \mathrm{mg} \text { or } \\
400 \mathrm{mg}\end{array}$ & $\begin{array}{l}\text { CZP } 200 \text { mg } 2 \text { weekly } \\
\text { in PASI > } 10 \text { and } \\
\text { BSA > 3\% } \\
\text { PASI75 } \\
\text { Week 24, 81\% } \\
\text { Week 48, 74\% } \\
\text { Week 96, 65\% }\end{array}$ \\
\hline $\begin{array}{l}\text { Reich } \\
{[17]}\end{array}$ & 2 & $\begin{array}{l}\text { British Journal of } \\
\text { Dermatology (2012) }\end{array}$ & $\begin{array}{l}\text { Randomised, double-blind study in patients with } \\
\text { CPP (PASI } \geq 12 \text { ) treated with CZP } 200 \mathrm{mg} / \\
400 \mathrm{mg} \text { weekly }\end{array}$ & $\begin{array}{l}\text { CZP } 200 \mathrm{mg} \\
\text { PASI75, 75\% } \\
\text { PASI90, 39\% } \\
\text { CZP } 400 \mathrm{mg} \\
\text { PASI75, 83\% } \\
\text { PASI90, } 47 \%\end{array}$ \\
\hline $\begin{array}{c}\text { Gottlieb } \\
\text { [15] }\end{array}$ & 1 & $\begin{array}{l}\text { Journal of American } \\
\text { Academy of } \\
\text { Dermatology (2018) }\end{array}$ & $\begin{array}{l}\text { Randomised control trial in patients with CPP } \\
\text { treated with placebo or } 200 \mathrm{mg} / 400 \mathrm{mg} \text { every } \\
2 \text { weeks }\end{array}$ & $\begin{array}{l}\text { At week } 16 \\
\text { Placebo } \\
\text { PASI75, 9.9\% } \\
\text { PASI90, 2.5\% } \\
\text { CZP } 200 \mathrm{mg} \\
\text { PASI75, 76.7\% } \\
\text { PASI90, 45.9\% } \\
\text { CZP 400 mg } \\
\text { PASI75, 82\% } \\
\text { PASI90, 52.2\% }\end{array}$ \\
\hline
\end{tabular}

The levels of evidence were determined on the basis of the criteria established at the Oxford Centre for Evidence Based Medicine

PASI Patient Area and Severity Index, BSA body surface area, CZP certolizumab, PsO psoriasis

treatment of rheumatoid arthritis, ankylosing spondylitis and PsA, with a starting dose of $400 \mathrm{mg}$ subcutaneously at weeks 0,2 and 4 , followed by maintenance treatment of $200 \mathrm{mg}$ every 2 weeks, with clinical response evaluated at week 12 [18-21]. Dermatologists understandably do not consider it within their armamentarium despite evidence from a phase 3 clinical trial in psoriasis. Additionally, we have shown that in patients with difficult to treat psoriasis, who have failed multiple biologics or who have developed secondary failure, certolizumab could be considered as an alternative and highly effective treatment. 
Unlike other TNF agents, the absence of a fragment crystallisable $(\mathrm{Fc})$ region in certolizumab changes key pharmacodynamic properties, including a lack of both complement-dependent cytotoxicity and antibody-dependent cell-mediated cytotoxicity [22]. The process of pegylation involves the covalent conjugation of proteins to polyethylene glycol, a process that is supposed to improve biopharmaceutical properties, e.g. increasing solubility, half-life and drug stability, while concurrently reducing renal excretion, antigenicity and immunogenicity [20]. Resultant potential therapeutic benefits include potential for subcutaneous administration, less frequent dosing, reduced generation of ADAbs and improved drug toxicity profile. We were able to demonstrate efficacy with certolizumab in one patient who we showed low adalimumab drug levels associated with ADAbs to adalimumab, but no other patients in this case series had this additional testing. The presence of ADAbs has been associated with decreased treatment efficacy with both infliximab and adalimumab although not etanercept [22-26]. In certolizumab, the presence of ADAbs and the impact on clinical efficacy remain uncertain as several papers have identified higher levels of circulating antibody than would be expected; however, it has been postulated that this may be secondary to the presence of the Fab fragment which is monovalent; thus, drug-ADAb complexes easily dissociate and can therefore be more easily detected [26]. A further potential benefit of certolizumab is evidence of reduced transfer across the placenta with very low or absent foetal drug levels suggesting that certolizumab may be safer into the third trimester of pregnancy compared to other anti-TNFs [20, 27, 28].

\section{CONCLUSIONS}

Although certolizumab prescribing is currently within the remit of rheumatologists, we have highlighted several papers within the literature that demonstrate that certolizumab is an effective treatment for psoriasis, with both a rapid mode of action and also a high percentage of patients achieving both PASI75 and PASI90.
Although not currently licensed for patients with psoriasis, we have found it advantageous to work collaboratively with our rheumatology colleagues who are able to prescribe alternative biologics not at our disposal, particularly for those patients who have proved difficult to treat with conventional treatments.

\section{ACKNOWLEDGEMENTS}

Funding. This work was supported by researchers at the National Institute for Health Research Manchester Biomedical Research Centre. No funding was received for article processing charges.

Authorship. All named authors meet the International Committee of Medical Journal Editors (ICMJE) criteria for authorship for this article, take responsibility for the integrity of the work as a whole, and have given their approval for this version to be published.

Disclosures. Richard Warren has research grants from AbbVie, Almirall, Amgen, Celgene, Janssen, Lilly, Leo, Novartis, Pfizer \& UCB and has received consulting fees from AbbVie, Almirall, Amgen, Boehringer Ingelheim, Celgene, Janssen, Leo, Lilly, Novartis, Pfizer, Sanofi \& UCB. Hectpr Chinoy has recieved educational grants and honoraria from UCB. David Rutkowski has nothing to disclose. Richard Warren is the Editor-in-Chief of this journal.

Compliance with Ethics Guidelines. This work was done as an anonymized audit on certolizumab use in a single tertiary referral centre and therefore informed consent was not required.

Open Access. This article is distributed under the terms of the Creative Commons Attribution-NonCommercial 4.0 International License (http://creativecommons.org/licenses/ by-nc/4.0/), which permits any noncommercial use, distribution, and reproduction in any medium, provided you give appropriate credit to the original author(s) and the source, provide 
a link to the Creative Commons license, and indicate if changes were made.

\section{REFERENCES}

1. Parisi R, Symmons DP, Griffiths CE, Ashcroft DM, Identification and Management of Psoriasis and Associated ComorbidiTy (IMPACT) project team. Global epidemiology of psoriasis: a systematic review of incidence and prevalence. J Invest Dermatol. 2013;133(2):377-85.

2. Eberle FC, Bruck J, Holstein J, Hirahara K, Ghoreschi $\mathrm{K}$. Recent advances in understanding psoriasis. F1000Res. 2016;5:770.

3. Ray-Jones H, Eyre S, Barton A, Warren RB. One SNP at a time: moving beyond GWAS in psoriasis. J Invest Dermatol. 2016;136(3):567-73.

4. Langley RG, Elewski BE, Lebwohl M, et al. Secukinumab in plaque psoriasis-results of two phase 3 trials. New Engl J Med. 2014;371(4):326-38.

5. Warren RB, Smith $\mathrm{CH}$, Yiu ZZ, et al. Differential drug survival of biologic therapies for the treatment of psoriasis: a prospective observational cohort study from the British Association of Dermatologists Biologic Interventions Register (BADBIR). J Invest Dermatol. 2015;135(11):2632-40.

6. Griffiths CE, Strober BE, van de Kerkhof P, et al. Comparison of ustekinumab and etanercept for moderate-to-severe psoriasis. New Engl J Med. 2010;362(2):118-28.

7. Tyring S, Gottlieb A, Papp K, et al. Etanercept and clinical outcomes, fatigue, and depression in psoriasis: double-blind placebo-controlled randomised phase III trial. Lancet. 2006;367(9504):29-35.

8. Yamauchi PS, Gindi V, Lowe NJ. The treatment of psoriasis and psoriatic arthritis with etanercept: practical considerations on monotherapy, combination therapy, and safety. Dermatol Clin. 2004;22(4):449-59.

9. Paller AS, Siegfried EC, Langley RG, et al. Etanercept treatment for children and adolescents with plaque psoriasis. New Engl J Med. 2008;358(3):241-51.

10. Chaudhari U, Romano P, Mulcahy LD, Dooley LT, Baker DG, Gottlieb AB. Efficacy and safety of infliximab monotherapy for plaque-type psoriasis: a randomised trial. Lancet. 2001;357(9271):1842-7.
11. Menter A, Griffiths CE. Current and future management of psoriasis. Lancet. 2007;370(9583):272-84.

12. Menter A, Feldman SR, Weinstein GD, et al. A randomized comparison of continuous vs. intermittent infliximab maintenance regimens over 1 year in the treatment of moderate-to-severe plaque psoriasis. J Am Acad Dermatol. 2007;56(1):e3115.

13. Gordon KB, Langley RG, Leonardi C, et al. Clinical response to adalimumab treatment in patients with moderate to severe psoriasis: double-blind, randomized controlled trial and open-label extension study. J Am Acad Dermatol. 2006;55(4):598-606.

14. Hsu L, Snodgrass BT, Armstrong AW. Antidrug antibodies in psoriasis: a systematic review. Brit J Dermatol. 2014;170(2):261-73.

15. Gottlieb AB, Blauvelt A, Thaçi $D$, et al. Certolizumab pegol for the treatment of chronic plaque psoriasis: results through 48 weeks from 2 phase 3, multicenter, randomized, double-blinded, placebo-controlled studies (CIMPASI-1 and CIMPASI-2). J Am Acad Dermatol. 2018;79(2):302-14.

16. Gottlieb AB, Kalb RE, Blauvelt A, et al. The efficacy and safety of infliximab in patients with plaque psoriasis who had an inadequate response to etanercept: results of a prospective, multicenter, openlabel study. J Am Acad Dermatol. 2012;67(4):642-50.

17. Reich K, Ortonne JP, Gottlieb AB, et al. Successful treatment of moderate to severe plaque psoriasis with the PEGylated $\mathrm{Fab}^{\prime}$ certolizumab pegol: results of a phase II randomized, placebo-controlled trial with a re-treatment extension. $\mathrm{Br} \mathrm{J}$ Dermatol. 2012;167(1):180-90.

18. Mease P, Deodhar A, Fleischmann R, et al. Effect of certolizumab pegol over 96 weeks in patients with psoriatic arthritis with and without prior antitumour necrosis factor exposure. RMD Open. 2015;1(1):e000119.

19. Tak PP, Kalden JR. Advances in rheumatology: new targeted therapeutics. Arthritis Res Ther. 2011;13(Suppl 1):S5.

20. Pasut G. Pegylation of biological molecules and potential benefits: pharmacological properties of certolizumab pegol. BioDrugs. 2014;28(Suppl 1):S15-23.

21. Mease P, Deodhar A, Fleischmann R, et al. Effect of certolizumab pegol over 96 weeks in patients with psoriatic arthritis with and without prior antitumour necrosis factor exposure. RMD Open. 2015;1(1):e000119. 
22. Nesbitt A, Fossati G, Bergin M, et al. Mechanism of action of certolizumab pegol (CDP870): in vitro comparison with other anti-tumor necrosis factor alpha agents. Inflamm Bowel Dis. 2007;13(11):1323-32.

23. Hsu L, Snodgrass BT, Armstrong AW. Antidrug antibodies in psoriasis: a systematic review. $\mathrm{Br} \mathrm{J}$ Dermatol. 2014;170(2):261-73.

24. Mahil SK, Arkir Z, Richards G, Lewis CM, Barker JN, Smith $\mathrm{CH}$. Predicting treatment response in psoriasis using serum levels of adalimumab and etanercept: a single-centre, cohort study. Br J Dermatol. 2013;169(2):306-13.

25. Lecluse LL, Driessen RJ, Spuls PI, et al. Extent and clinical consequences of antibody formation against adalimumab in patients with plaque psoriasis. Arch Dermatol. 2010;146(2):127-32.
26. Jani M, Isaacs JD, Morgan AW, et al. High frequency of antidrug antibodies and association of random drug levels with efficacy in certolizumab pegoltreated patients with rheumatoid arthritis: results from the BRAGGSS cohort. Ann Rheum Dis. 2017;76(1):208-13.

27. Brown D, Nesbitt A, Stephens S, Foulkes R. Lack of placental transfer and accumulation in milk of an anti-TNF PEGylated $\mathrm{Fab}^{\prime}$ fragment in rats. Inflamm Bowel Dis. 2007;13(5):656.

28. Porter C, Armstrong-Fisher S, Kopotsha T, et al. Certolizumab pegol does not bind the neonatal Fc receptor (FcRn): consequences for FcRn-mediated in vitro transcytosis and ex vivo human placental transfer. J Reprod Immunol. 2016;116:7-12. 